\title{
Alternating hemiplegia: complicated migraine of infancy
}

\author{
GWILYM P. HOSKING, NICHOLAS P. C. CAVANAGH, AND JOHN WILSON \\ From the Department of Clinical Neurology, The Hospital for Sick Children, London
}

SUMMARY Alternating hemiplegia in children is a rare form of 'complicated' migraine. There are a number of similarities to seizure disorders and correct diagnosis may prove difficult. The clinical features of 6 patients with alternating hemiplegia are presented together with the results of electrophysiological, radiological, and biochemical studies. While there were a number of clinical similarities between the patients, extensive investigations failed to demonstrate significant abnormalities. Although a diagnosis of a seizure disorder was suggested at some time in all of the patients, in only 2 was it certain there was a fit. Headaches occurred in the eldest patient (although not always with a hemiplegic attack) while in the younger patients misery often accompanied their attacks. Intellectual status was impaired in 5 patients, although in 2 of these the cause was most likely to be perinatal difficulties. Response to various forms of treatment was generally not encouraging and concern is expressed that this alternating hemiplegia of childhood may carry an unfavourable prognosis.

Hemiplegic migraine is a well recognised form of 'complicated' migraine and is fully reviewed by Bruyn (1968). Although most reports concern adults, careful histories often reveal that the onset of symptoms was in childhood. There have been studies of migraine in children including the preschool age group in whom transient pareses have been observed (Burke and Peters, 1956; Holguin and Fenichel, 1967; Isler, 1971).

Alternating hemiplegia on the other hand is a much less well known form of 'complicated' migraine and refers to transient weakness of one side of the body. Occasionally both sides may be affected simultaneously. The first record of such cases was by Clarke (1910) and since then there have been papers by Dynes (1939), Symonds (1952), Verret and Steele (1971), and Golden and French (1975). The apparent rarity of this condition, and some of the similarities that it bears to seizure disorders, inevitably gives rise to diagnostic difficulty. In this paper we review both the clinical features of 6 children who have been under our care with this disorder for several years, and the previous literature.

\section{Patient studies}

The principal clinical features of our 6 children are Received 19 January 1978 summarised in Table 1. The histories of Cases 2 and 6 are given in greater detail as they are representative of the whole group.

Case 2. A 29-month-old boy whose father and paternal grandmother had severe classical migraine. He was born after a normal pregnancy and delivery and his early development was also normal. At age $3 \frac{1}{2}$ months he had a left-sided seizure lasting a few minutes followed by a Todd's paralysis of that side lasting several hours. Two further similar episodes occurred on the left side at $7 \frac{1}{2}$ and 13 months.

At age 18 months he had an episode of hemiparetic weakness on the right side but this was not accompanied by a seizure. He has subsequently had episodes of hemiparetic weakness on either side. Between ages 18 months and 2 years his right-sided pareses were not associated with seizures, while approximately half on the left-side were, but in these the seizure followed the weakness rather than preceded it.

Since age 2 years he has continued to have frequent alternating weakness of either side and seizures have not recurred. On some occasions both sides have been affected together but the onset has never been simultaneous. When both sides are affected he is unable to sit and has difficulty in eating. These attacks, which are sudden in onset and associated with misery and crying, last between 5 and 7 days. 
Table 1 Summary of clinical features

\begin{tabular}{|c|c|c|c|c|c|c|c|c|c|}
\hline Case no. & $\operatorname{Sex}$ & $\begin{array}{l}\text { Age } \\
\text { (years) }\end{array}$ & $\begin{array}{l}\text { Family } \\
\text { history of } \\
\text { migraine }\end{array}$ & $\begin{array}{l}\text { Age of } \\
\text { onset } \\
\text { (months) }\end{array}$ & $\begin{array}{l}\text { Duration of } \\
\text { attacks } \\
(\text { days })\end{array}$ & Dysphasia & Seizures & $\begin{array}{l}\text { Swallowing diffculty } \\
\text { with attacks }\end{array}$ & Other \\
\hline 2 & $\mathbf{M}$ & $2 \cdot 4$ & + & 18 & $5-7$ & - & + & Occasional & See full description \\
\hline 3 & $\mathbf{F}$ & $2 \cdot 7$ & + & 5 & $\frac{1}{2}-3$ & + & + & - & \\
\hline 4 & $\mathbf{M}$ & 7 & - & 6 & $2-3$ & $\begin{array}{l}\text { No speech } \\
\text { developmer }\end{array}$ & nt & When both sides affected & $\begin{array}{l}\text { Severe retardation; } \\
\text { ? related to neonatal } \\
\text { hypoglycaemia }\end{array}$ \\
\hline 5 & $\mathbf{F}$ & 9 & + & 9 & $5-10$ & - & - & -3 & $\begin{array}{l}\text { Slow early develop- } \\
\text { ment, low intelligence }\end{array}$ \\
\hline 6 & $\mathbf{F}$ & 13 & + & 5 & $2-7$ & - & - & When both sides affected & See full description \\
\hline
\end{tabular}

From the age of 18 months his general development has slowed with no development of speech and walking, although he learnt to stand at the age of 2 years.

Case 6. A 13-year-old girl whose mother had classical migraine. The pregnancy was complicated by mild hypertension and proteinuria. Delivery at term was precipitate and there was some cerebral irritability in the neonatal period and feeding difficulties. Early development was slow. From age 5 months this girl had attacks of hemiparetic weakness which affected either side. The onset of the hemiparesis was usually sudden and often precipitated by minor emotional trauma. The weakness was usually severe, and often associated with misery. Skin blanching was often observed on the affected side. When both sides were affected together misery was extreme, and swallowing difficulties were usually present. The frequency of attacks has been variable with up to 6 attacks a month. There has been a decrease in more recent times. The duration of attacks is between 2 and 7 days, the recovery being gradual. Since age 9 years this girl has also complained of headaches. During the last few years she has developed mild choreiform movements.

\section{Seizures}

Although a diagnosis of epilepsy has been suggested at one stage in all our patients, we are sure of the occurrence of fits in only 2 children.

\section{Headache}

The eldest patient complained of headaches as she grew older, while misery, perhaps indicative of headache, accompanied the attacks in most of the younger patients.

\section{Intellectual status}

One of our patients (Case 4) is severely retarded, and although he suffered from neonatal hypoglycaemia there is evidence to suggest that he is progressively deteriorating. Another child (Case 6) has had slow development because of maternal toxaemia. Three of the remaining 4 children (Cases 1,2, and 5) have low developmental or intellectual status.

\section{Investigations}

A summary of the investigations carried out in our patients is given in Table 2.

Electrophysiological (EEG) studies have been carried out on all our patients during attacks and between them. Little variation has been seen in attacks except in Case 6 in which a lowering of the amplitude of the visually evoked response was noted during one attack (Dr G. F. A. Harding). EEG telemetry carried out in Case 5 added no further information to that obtained by more routine methods. When slow wave abnormalities were noted these were diffuse and did not lateralise either during an attack or between attacks.

Table 2 Investigations

\begin{tabular}{|c|c|c|c|}
\hline $\begin{array}{l}\text { Case } \\
\text { no. }\end{array}$ & $E E G$ & Radiology & $\begin{array}{l}\text { Blood ammonia and } \\
\text { amino-acids }\end{array}$ \\
\hline 1 & Slow wave excess & $\begin{array}{l}\text { L. carotid angio- } \\
\text { gram } \\
\text { CT scan * }\end{array}$ & Normal \\
\hline 2 & $\begin{array}{l}\text { Slow and fast } \\
\text { excess }\end{array}$ & CT $\operatorname{scan} *$ & Normal \\
\hline 3 & $\begin{array}{l}\text { Slow and fast } \\
\text { excess }\end{array}$ & CT $\operatorname{scan}{ }^{*}$ & Normal \\
\hline 4 & Slow wave excess & $\begin{array}{l}\text { Bilateral carotid } \\
\text { angiogram }\end{array}$ & Normal \\
\hline 5 & $\begin{array}{l}\text { Irregular slow } \\
\text { waves }\end{array}$ & $\begin{array}{l}\text { R. carotid angio- } \\
\text { gram } \\
\text { CT scan * }\end{array}$ & Normal \\
\hline 6 & Slow wave excess & $\begin{array}{l}\text { Bilateral carotid } \\
\text { angiogram } \\
\text { Arch aortogram } \\
\text { Vertebral angio- } \\
\text { gram } \\
\text { Air encephalogram }\end{array}$ & Normal \\
\hline
\end{tabular}

*Computerised axial tomography. 
Neuroradiological studies (see Table 2) have been carried out in all the patients, and in the older children these have been extensive. All these results have been negative.

Measurement of cerebral blood flow in conjunction with a right carotid angiogram was carried out in Case 5. In this study isotope was injected intraarterially and an indication of cerebral blood flow was obtained in 16 scalp detectors. Because 'normal' children do not have such investigation there are no control data, but in our patient the 'resting' flow was higher than expected, and on hyperventilation there was a very marked reduction in flow, particularly in the detectors over the temporal lobe.

Comprehensive biochemical investigations during and between attacks were consistently normal.

\section{Discussion}

The similarities among our 6 patients in their clinical phenomenology suggest that these children represent a clinical entity. There has been a failure to explain the clinical problems in these children on a basis of a large vessel structural abnormality, a metabolic defect, or through EEG investigations.

There is a family history of migraine in close relatives in 4 of our patients. The older children acknowledged that some of their hemiplegic episodes were accompanied by headache although this association was not invariable, and in the younger children accompanying misery in an attack suggested possible pain. Two (Cases 5 and 6) had episodic headaches not associated with weakness, but these were not characteristically migrainous. Clarke (1910) who first described alternating hemiplegia also suggested that it had a migrainous basis. Although no radiology was performed to exclude a vascular malformation, his 3 patients from 3 generations of one family all had headaches with their hemiplegic attacks. All Dynes's patients had headaches which came on once the weakness had developed and were always on the opposite side of the head (Dynes, 1939). His 2 patients had the typical aura symptoms of classical migraine including parasthesiae, blurred and hemianopic vision, and dysphasia. The belief that there is a migrainous basis to alternating hemiplegia is also maintained by the accounts of later papers (Verret and Steele, 1971; Golden and French, 1975) and in these there is ample evidence from both radiographic studies and a study at necropsy in Golden's Case 3 to exclude underlying vascular abnormalities.

Not only is there a strong family history of migraine in patients with alternating hemiplegia, but there may also be a strong and close family history of the alternating hemiplegia itself. Parent and child were similarly afflicted in the cases reported by Clarke (1910), Dynes (1939), Symonds (1952), and siblings similarly affected in some cases reported by Clarke (1910) and Verret and Steele (1971). It is also interesting to note that there may be a history of parents or siblings suffering from nonalternating hemiplegic migraine, so that both forms of complicated migraine may coexist within one family.

The early papers referring to hemiplegic migraine note the onset of symptoms in middle and late childhood, but it is clear from later papers (Verret and Steele, 1971; Golden and French, 1975) that symptoms may occur early in infancy. Our findings confirm this.

It is interesting to speculate upon the anatomical localisation of the cerebrovascular involvement. Golden and French (1975) were of the opinion that their patients suffered from vertebrobasilar migraine, since they thought it would be difficult to explain the accompanying ataxia in any other way, and they also noted that there was never any associated ipsilateral facial weakness. The accepted view of hemiplegic migraine is that the hemiplegia is consequent upon the vasoconstriction of the vessels of the contralateral hemisphere (Whitty, 1953), and certainly unilateral symptoms may be exacerbated by the injection of contrast medium into the contralateral internal carotid artery. Dynes's observation that visual symptoms and dysphasia were present whichever side of the body was hemiparetic suggests brain stem involvement, and the relatively common difficulty of swallowing encountered in our patients also supports this. Dysphasia was a relatively rare symptom in this and in Verret's series.

The response of our patients to treatment with anticonvulsants and to several other drugs used in the management of migraine, including clonidine in doses up to $0.025 \mathrm{mg}$ t.d.s., has been generally poor, although in one (Case 5) there has been a good response to clonidine and phenytoin given together (phenytoin $2 \mathrm{mg} / \mathrm{kg}$ per day, clonidine $2.5 \mathrm{mg} / \mathrm{kg}$ per day). The use of ergot derivatives and methysergiside has been eschewed because of the risk of cerebral ischaemia.

Our experience confirms the impressions of Symonds (1952), Verret and Steele (1971), and Golden and French (1975), that the prognosis of alternating hemiplegia is not always good. Recent studies using computerised axial tomography on patients with severe long-standing migraine have demonstrated cortical atrophy in many patients (Hungerford et al., 1976). Our experience with alternating hemiplegia suggests that this disorder may lead to progressive intellectual deterioration and persistent neurological deficits. 
We thank Dr G. F. A. Harding of the Department of Neuropsychology at the University of Aston for permission to describe results of studies on visually evoked responses performed in Case 6; the Department of Neurophysiology of the National Hospital, Queen's Square, for EEG telemetry studies carried out in Case 5; and the Cerebral Blood Flow Research Group of the National Hospital for carrying out cerebral blood flow studies in that patient.

\section{References}

Bruyn, G. W. (1968). Complicated migraine. In Handbook of Clinical Neurology, volume 5, chapter 6, pp. 59-95. Edited by P. J. Vinken and G. W. Bruyn. North Holland: Amsterdam.

Burke, E. C., and Peters, G. A. (1956).Migraine in childhood: a preliminary report. American Journal of Diseases of Children, 92, 330-336.

Clarke, J. M. (1910). On recurrent motor paralysis in migraine, with a report of a family in which recurrent hemiplegia accompanied the attacks. British Medical Journal, 1, 1534-1538.
Dynes, J. B. (1939). Alternating hemiparetic migraine syndrome. British Medical Journal, 2, 446-447.

Golden, G. S., and French, J. H. (1975). Basilar artery migraine in young children. Pediatrics, 56, 722-726.

Holguin, J., and Fenichel, G. (1967). Migraine. Journal of Pediatrics, 70, 290-297.

Hungerford, G. D., du Boulay, G., and Zilkha, K. J. (1976). Computerised axial tomography in patients with severe migraine: a preliminary report. Journal of Neurology, Neurosurgery, and Psychiatry, 39, 990-994.

Isler, W. (1971). Acute Hemiplegias and Hemisyndromes in Childhood. Clinics in Developmental Medicine 41/42. Heinemann Medical: London.

Symonds, C. (1952). Migrainous variants. Transactions of the Medical Society of London, 67, 237-250.

Verret, S., and Steele, J. C. (1971). Alternating hemiplegia in childhood: a report of eight patients with complicated migraine beginning in infancy. Pediatrics, 47, 675-680.

Whitty, C. W. M. (1953). Familial hemiplegic migraine. Journal of Neurology, Neurosurgery, and Psychiatry, 16, 172-177.

Correspondence to Dr G. P. Hosking, The Ryegate Centre (The Children's Hospital), Sheffield S10 5DD. 